\title{
Progressive failure analysis of composite laminated stiffened plates using the finite strip method
}

\begin{abstract}
A finite strip method for non-linear static analysis based on the tangential stiffness matrix has been developed using the new concept of polynomial finite strip elements, with Mindlin (first-order shear deformable element) plate-bending theory for composite plates. A progressive failure algorithm for composite laminates has been successfully developed for the new finite strip methods using a stress-based failure criterion, Tsai-Wu. A finite strip analysis programming package which is capable of performing non-linear progressive damage analysis for composite stiffened plates and shells has also been developed with Mindlin plate-bending element. Good agreement with the finite element results has been observed through various test cases, confirming the accuracy and reliability of the new developed method.
\end{abstract}

Keyword: Finite strip methods, Mindlin's plate-bending theory, Tangential stiffness matrix, Progressive failure analysis 